(c) 2010 IEEE. Personal use of this material is permitted. Permission from IEEE must be obtained for all other uses, in any current or future media, including reprinting/republishing this material for advertising or promotional purposes, creating new collective works, for resale or redistribution to servers or lists, or reuse of any copyrighted component of this work in other works. 


\title{
A Knapsack Problem Approach For Achieving Efficient Energy Consumption in Smart Grid for End- users' Life Style
}

\author{
Omid Ameri Sianaki, Omar Hussain and Azadeh Rajabian Tabesh \\ Digital Ecosystem and Business Intelligence Institute \\ Curtin University of Technology \\ Perth, Australia \\ Omid.AmeriSianaki@postgrad.curtin.edu.au \\ \{O.Hussain, A.RajabianTabesh\}@curtin.edu.au
}

\begin{abstract}
In order to achieve an efficient energy consumption level in the residential sector of a smart grid, the end-users are equipped with various smart home energy controller technologies. The devices are provided to inform the consumers about their consumption pattern by showing or sending different kinds of consumptional information to them. This kind of information is provided to assist them in making decisions about altering their consumption behaviour or to urge them to modify their life style during peak hours. We propose that the energy home controllers should offer preferred and optimal scenarios to support end-users when making a decision about their consumption. Effective scenarios should emerge from consumer's life style and preferences. In this paper, we will apply AHP methodology to quantify the consumer's preferences for using appliances during peak periods when the price has increased, and use the Knapsack problem approach to achieve the optimal solution for managing the appliances. With this approach, not only will the cost of electricity not escalate during peak hours, but also user preferences, satisfaction and minimum change to current life style will be considered.
\end{abstract}

Keywords-smart grid; dynamic pricing; energy consumption management; analytic hierarchy process; knapsack problem

\section{INTRODUCTION}

Smart Grid is an electricity network that can intelligently integrate the actions of all users connected to it in order to efficiently deliver sustainable, economical and secure electricity supplies [1]. In this system, the consumers apart from just consuming, also produce energy from different sources and simultaneously replenish or use it during peak times. In such architecture, the need for two-way communication is at the heart of all Smart Grid initiatives. In this fashion, both parties work synergistically to manage the cost, delivery and environmental impact of power generation and energy services delivery. But to achieve energy efficiency, apart from having such architecture, mechanisms are needed that add intelligence to it at different levels. The type of intelligence to be added varies according to the level at which it is being considered. For example, from the generation perspective, one of the areas in which intelligence has to be added is dynamic pricing; whereas from the consumer perspective, it may be in the efficient utilization of energy at the home level based on the price. This is supported by Schneider Electric [2] which states that energy management needs intelligence not only to reduce energy consumption, but also to reduce operational costs.

Achieving efficient level of electricity consumption by increasing end-users' participation is one of the main goals of the smart grid. The integration of ubiquitous information communication technologies along the grid have certainly allowed utility providers to have more collaboration with their consumers and also to give them more awareness about their energy consumption pattern. The use of a dynamic pricing mechanism and the provision of real-time feedback for endusers are conducted via website portals, mobile phones or consumption viewer feedback devices at the end-user side such as a wireless PowerCost Monitor home energy meter or InHome Displays (IHD). These comparative and historic realtime feedback devices are designed to give consumers a better understanding of their energy use and to motivate them to alter their consumption for regulating household electrical demand to an optimal level during on and off peak time periods. As a result, when consumers receive informational feedback or price signals during peak hours, they try to monitor and to limit their electricity consumption by making a real-time decision about their consumption of various electrical appliances. This will produce a change in the lifestyle pattern of a user that is dependent on activities with regards to price signals, time, priority of using appliances and budgeting that in these fashion householders make decision in a way of self-realization. Even though the consumers are equipped with smart appliances and smart thermostats, there is the need for an intelligent decision support system coupled with a smart meter for supporting the end-users' control and integration of the total usage time, budget and their preferences. In the literature, many approaches have identified several variables that are important for energy conservation in residential sectors [3-13]. Energy consumption models [14-16] have been specified for achieving profile forecasts or loads and demand management for beneficiary of macro level of electricity energy management. But none of 
these approaches presents a solution for measuring consumers' preferences for managing their energy consumption when the price is higher during peak hours and also, there are no tools or techniques allowing end-users to create a balance between their life style, and budget and efficient energy consumption.

Many socio-economic factors incorporated into residential energy consumption models like household income, age and numbers of children and adults at home, have been studied by researchers $[14,15,17]$. The main purpose of these factors is to determine the energy consumption pattern. It was determined that various socio-economic factors had an affect on the efficient consumption of energy. For instance, regarding the age factor, Sardianou [18] argued that commonly, older people adopt fewer energy conservation strategies because they have less formal education and lack energy know-how. He also indicated that attitudes and also the numbers of children and adults at home indicate that there are different attitudes and preferences; hence, there may be several people involved in making decisions about how energy should be consumed in the home. All of such consumer preferences factors need to be captured for having an efficient energy consumption model.

In current smart grid systems like direct load control or demand response that we will discuss about them in next section, consumers are forced to shift their usage from peak periods to non-peak hours or to turn off specific electrical devices like air conditioners, thereby affecting their life style and comfort. Currently, there are no supports for consumers that guide them to decide which appliances should operate and for how long, so that optimal consumption levels during peak hours is avoided, and lifestyle preferences are not compromised.

In this paper, for achieving and quantifying the consumers' preferences for using appliances in peak periods, we will apply the Analytic Hierarchy Process (AHP) as a structured technique and then discuss how the preferences will affect total energy management consumption. Then, using a dynamic programming approach such as the Knapsack algorithm, we will show how this technique is useful for managing the optimal use of appliances during peak periods with the goal of saving the family's utility budget and preferences.

\section{DEMAND RESPONSE}

In Smart Grid, demand side management (DSM) was originally conceived to include any action on the demand side that changes the shape of a customer's energy load profile. Demand Response (DR) activities are defined as "actions voluntarily taken by a consumer to adjust the amount or timing of his energy consumption. Actions are generally in response to an economic signal (e.g. energy price, or government and/or utility incentive) [19]." Demand response" is a reduction in demand designed to reduce peak demand or avoid system emergencies. In this regard, demand response can be a more cost-effective alternative than adding generation capabilities to meet the peak and/or occasional demand spikes [20]. The underlying objective of DR is to actively engage customers in modifying their consumption in response to pricing signals. The goal is to reflect supply expectations through consumer price signals or controls and enable dynamic changes in consumption relative to price. DSM is focused on achieving sustained energy use reductions and is often driven by incentives, whereas DR is market driven and results in temporary reductions or temporal shifts in energy use[19]. There are three ways to achieve DR: (a) Price response that refers to situations where customers voluntarily reduce energy demand due to high prices during times of peak demand, (b) Demand bidding programs are available when customers are willing to reduce or forgo their consumption of electricity at a certain predetermined price. One enabling technology is a programmable thermostat which controls the air-conditioning and heating systems. The thermostat can be programmed to adopt different settings depending on the electricity price levels. The thermostats can also have a notification feature to alert residents of calls for action, as well as an override feature in case the customer chooses not to participate in the particular event [21]. Various internet-based programs are also being developed. Here, the customer obtains information on buyback rates via internet connections and takes appropriate action to manage peak loads. A key issue in these programs is how sophisticated or complex to make the price signals[21], and (c) Voluntary load shedding which refers to situations where customers voluntarily reduce energy demand in response to appeals from the government during times of high demand and/or constrained supply. Dynamic pricing has two important attributes. First, it provides price signals to customers to motivate them to shift their usage from high-priced to lowpriced hours of the day. Second, the price is determined based on the real cost of electricity on a given day, so they have the potential to (1) lower the market clearing price, and (2) reduce the need for new peaking plants. Just as customers respond to prices in other markets, there is sufficient evidence that customers do respond in a predictable and quantifiable way to dynamic electricity prices [22]. As a result, all demand response programs are designed in such a way that the electricity consumption can be cut or shifted from on-peak hours to an off-peak period without considering the consumers' preferences, budget and lifestyle.

In the next sections, we will review previous literatures about informational energy feedback used in DR and those approaches that are concerned with consumption feedbacks, and literatures showing that consumer preferences in managing the electricity consumption are ignored. Also, we will show with an example how a dynamic programming approach is able to evaluate consumers' preferences regarding energy consumption.

\section{THE ENERGY CONSUMPTION FEEDBACK FOR HOUSEHOLD}

There are numerous studies on the effect of end-users' electrical information feedback via smart meters and displays as a vigorous conservation mechanism in the residential sector with the aim of increasing end-users' participation in managing their energy consumption [4-6, 9-11, 23]. The effects of these feedbacks vary according to the policies and ICT tools which are employed. In Smart Grid, the main goal of all those feedbacks is to control the energy demand by supporting endusers with real-time information and encouraging them to give a demand response. Faruqui et al. [6] have reviewed various 
pilot programs launched during 1998 and 2008. Their survey revealed the level of consumers' responsiveness to the direct feedback provided by in-home displays. They claimed that $7 \%$ of electricity power in a non-prepayment electricity system and about $14 \%$ in the pre-pay program have been conserved by consumers who had used an IHD. As a result of this approach, they indicate that the other factors such as: "dwelling condition, occupant consulting with a reliable advisor, and the support from utilities and government for the technical, training and social infrastructure to make learning and change possible" play an important role in interaction with feedback. They also believe that the sustainability of the IHDs' impact should be tested when they are used to motivate individuals to change their consumption behaviors and to save energy, because consumers may initially respond to the direct feedback, although over time, they may lose enthusiasm and perceive it as a physical reminder. This point is also considered by $\mathrm{S}$. Darby [5] - that more consideration needs to be given to ways of changing individuals' habits and improving feedback outcomes; this will be achieved when commitment, advice and information are coupled with the IHD. Feedback should be in conjunction with incentives to save energy and behaviour may change, but the changes are likely to slowly disappear when the incentives decrease or disappear. Wood et al. [10] used a detailed approach for assessing the effect of information feedback in domestic cooking for consumer and they observed that the positive feedback from householders reduced the rates of energy consumption. They indicated that although saving money is often the most important motivator, if energy were to be displayed in pence and pounds, the user may have been dissuaded from saving energy due to the small financial savings. If the consumers realize that they are only saving pennies per day then they may be demotivated, rather than being enthusiastic about saving energy. As a result, the effectiveness of the energy information feedback is coupled with financial saving aspect at the end-user side. Ueno et al.[9] provided an on-line interactive "energy-consumption information system" that displays power consumptions of, at most, 18 different appliances and their experiment showed that by applying this feedback, the total power consumption decreased by $18 \%$ and residents saved energy for various appliances such as TVs, electric pots, and space-heating appliances. Newsham et al. [7] reviewed a demand response strategy in North America for householders' summer peak electricity consumption and specified that a "critical peak pricing program with enabling technology to automatically curtail loads on event days is the most effective strategy and the householders would not suffer by it, provided that they have been informed by information clarifying which load are controlled and how, and have an override option".

The abovementioned approaches indicate that the role of the end-users and the level of their awareness of their consumption behaviour are significant in total grid energy management. On the other hand, consumers use a variety of appliances for their requirements and welfare, and their decision making regarding the use of appliances is a complicated process. Yamamoto et al. [12] revealed that the payment system, characteristics of appliances and human psychology all contribute to this process. In the next section, we will propose the application of the Analytic Hierarchy
Process (AHP) as a means of ascertaining the preferences of end-users for using appliances during peak hours and will specify those appliances the use of which during peak periods will save money for consumers.

\section{CONSUMERS' DECISION MAKING FOR CONTROLLING APPLIANCES USAGE}

A survey of 'end-users' decision-making in electrical appliance use" conducted by Yamamoto et al. [12] supported the assumption that electricity consumption by householders is not always rational and is influenced by the payment system along with human psychology factors. Consumers use different electrical devices for different purposes. They have no clear understanding of kilowatts but they understand dollars well and consequently they consume according to the amount of money stated on their bills. If householders have a specific budget for their electricity bill, they will judge their consumption behaviour by comparing periodic bills. In a dynamic pricing system, it is difficult to create a balance between the electricity budget and usage because householders have learnt to alter the energy consumption by decreasing the amount of consuming time, and if the price is increased during the peak period, then the reduced power consumption does not have any effect on the bill; moreover, it would be difficult to maintain a certain lifestyle and simultaneously economize on energy consumption. In the next section, in order to arrive at a good understanding of end-users' consumption behaviour during peak hours, we will provide a scenario as an example that illustrates a consumer's selection of electrical devices that $\mathrm{s} / \mathrm{he}$ likes to use during peak hours when the price has increased, but without increase the cost of electricity consumed. Therefore, by applying an analytic hierarchy process technique, we will build a hierarchy of appliances according to a consumer's preferences, and then using the zero-one Knapsack problem algorithm, we will select the appliances with maximum total value; by 'value', we mean those appliances whose use is of the highest importance according to the enduser's lifestyle and preferences.

\section{A. Analytic Hierarchy Process (AHP) for quantifying end- users' preferences}

Structuring any decision problem hierarchically is an efficient way of dealing with complexity and identifying the major components of the problem [24]. The Analytic Hierarchy Process (AHP) is a common theory of measurement. It is used to derive ratio scales from both discrete and continuous paired comparisons. These comparisons may be taken from actual measurements or from a fundamental scale which reflects the relative strength of preferences and feelings [25]. In this approach, we define a scenario that provides a good example of AHP application for ranking the consumers' preferences for using appliances during peak hours when the price of electricity has increased. We have assumed that there is an end-user who judges seven appliances. These appliances, as shown in Table I, are Dishwasher (DW), Home computer (HC), Hair dryer (HD), Iron (IR), Spa Bath (SB), Television (TV), and Vacuum Cleaner (VC). Our goal in this scenario is 
to rank the appliances according to several criteria that will be used by the consumer to ascertain their level of importance to him. We asked the consumer to compare his use of electrical devices based on priority in a pairwise comparison, according to criteria during peak hours when price rate has increased from $\$ 0.15 \mathrm{~kW} . \mathrm{h}$ to $\$ 0.2 \mathrm{~kW} . \mathrm{h}$ at peak period. The criteria are: emergent usage, welfare and enjoyment derived from using appliances, and the cost of electricity as shown by a hierarchy model in Fig. 1. The consumers use appliances for their emergency, welfare or enjoyment needs. For example, from a student viewpoint, using a computer during peak hours can be considered as an emergent need, whereas it may be an enjoyment for a mature adult. In the next sections, we will expand on our methodology. After creating a hierarchical model, the priorities are established among the elements of the hierarchy by making judgments based on the pairwise comparisons. For example, by comparing the appliances, the consumer might say he prefers to have emergent use of appliances during peak hours even if the price rate increases, or he might prefer to enjoy using appliances regardless of the cost, or conversely, he might prefer to save money and not to use the appliances that bring him enjoyment during peak hours. Then, in order to arrive at a set of overall priorities for the hierarchy of all appliances, the judgments will be synthesized for each criterion. For example, the consumer will judge the level of emergent use of his seven appliances according to the most emergent to less emergent one according to his preference. We used the Expert Choice software, EC11.5 [26] to arrive at the consumer judgment about each element and also to process and to measure the hierarchy. The result of the numerical priority of criteria and alternatives are presented at Table II. The inconsistency value of judgment in this scenario for all measurements was less than 0.0002, meaning that the user has an acceptable level of consistency in his judgment.

As a result, it is specified that according to four criteria of emergency usage of appliances, welfare and enjoyment derived from them and the electrical cost of usage, when the electrical price rate increases from $0.15 \$ / \mathrm{kW}$.h to $0.2 \$ / \mathrm{kW}$.h at peak hours, the consumer prefers to use Spa Bath with highest priority and Iron with lowest priority. The final preference ranking is presented in Table III.

By quantifying the consumer's preference using the AHP method in Section A, the priority level of using the appliances as shown in Table III was achieved. If the consumer would like to maintain his lifestyle during peak hours and not change his consumption behavior, then he should pay for it. But if he decides to not exceed from his budget, then he should alter his consumption and turn off some appliances and shift the consumption to off-peak hours. In our scenario, the energy cost for one hour during off-peak was \$ 0.896 and it was increased to $\$ 1.195$ at peak time. Now the question is: which appliances should be turned off during peak hours in order that the total cost not be exceeded?

By considering the hierarchy of preferences when Iron, Hair dryer, Television and Vacuum cleaner are off, then the total cost during peak time would be $\$ 0.88$ and the consumer would be able to use Spa Bath, Dishwasher and Home computer which have the highest rank according to his preferences. It is significant that this particular decision is the preferred solution. In order to achieve the optimal choice, we will apply knapsack problem in the next section.

TABLE I. APPLIANCE SPECIFICATION

\begin{tabular}{|l|c|c|c|c|c|}
\hline \multirow{5}{*}{ Appliance } & $\begin{array}{c}\text { Power - } \\
\boldsymbol{k} \boldsymbol{W}\end{array}$ & $\begin{array}{c}\text { Hour of } \\
\text { usage }\end{array}$ & $\begin{array}{c}\text { Off-peak } \\
\text { time cost- } \\
\$\end{array}$ & $\begin{array}{c}\text { On-peak } \\
\text { time cost- } \\
\$\end{array}$ \\
\hline 1 & $\begin{array}{c}\text { Spa bath with 5 } \\
\mathrm{kW} \text { heater }\end{array}$ & 4.933 & 0.5 & 0.373 & 0.493 \\
\hline 2 & Dishwasher & 1.867 & 1.0 & 0.28 & 0.373 \\
\hline 3 & Home computer & 0.067 & 1.0 & 0.01 & 0.013 \\
\hline 4 & Vacuum cleaner & 0.933 & 0.5 & 0.07 & 0.093 \\
\hline 5 & Television & 0.200 & 1.0 & 0.03 & 0.40 \\
\hline 6 & Hair dryer & 1.467 & 0.3 & 0.066 & 0.088 \\
\hline 7 & Iron & 0.933 & 0.5 & 0.07 & 0.093 \\
\hline The cost of electricity during one hour use: & 0.896 & 1.195 \\
\hline
\end{tabular}

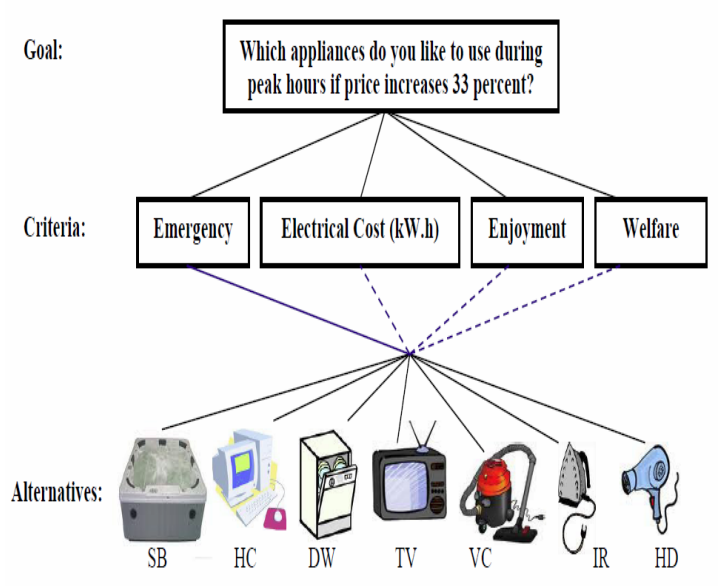

Figure 1. AHP hierarchy for making priority 
TABLE II. NUMERICAL PRIORITY DERIVED FOR EACH ELEMENT OF THE HIERARCHY

\begin{tabular}{|c|c|c|c|c|c|c|c|c|}
\hline \multicolumn{9}{|c|}{ Numerical priorities } \\
\hline \multirow{2}{*}{ 萄 } & \multicolumn{2}{|c|}{1} & \multicolumn{2}{|c|}{2} & \multicolumn{2}{|c|}{3} & \multicolumn{2}{|r|}{4} \\
\hline & \multicolumn{2}{|c|}{$\begin{array}{c}\text { Emergency } \\
0.358\end{array}$} & \multicolumn{2}{|c|}{$\begin{array}{c}\text { Electricity } \\
\text { Cost } \\
0.313\end{array}$} & \multicolumn{2}{|c|}{$\begin{array}{c}\text { Welfare } \\
0.247\end{array}$} & \multicolumn{2}{|c|}{$\begin{array}{c}\text { Enjoyment } \\
0.082\end{array}$} \\
\hline 1 & $\mathrm{HC}$ & 0.324 & SB & 0.412 & DW & 0.262 & SB & 0.331 \\
\hline 2 & DW & 0.190 & DW & 0.313 & TV & 0.188 & TV & 0.282 \\
\hline 3 & SB & 0.152 & IR & 0.078 & SB & 0.169 & $\mathrm{HC}$ & 0.169 \\
\hline 4 & $\mathrm{VC}$ & 0.125 & $\mathrm{VC}$ & 0.078 & $\mathrm{VC}$ & 0.167 & DW & 0.093 \\
\hline 5 & HD & 0.098 & $\mathrm{HD}$ & 0.074 & $\mathrm{H} \mathrm{C}$ & 0.159 & $\mathrm{HD}$ & 0.053 \\
\hline 6 & TV & 0.062 & TV & 0.034 & IR & 0.033 & $\mathrm{VC}$ & 0.043 \\
\hline 7 & IR & 0.048 & $\mathrm{HC}$ & 0.011 & $\mathrm{HD}$ & 0.021 & IR & 0.029 \\
\hline
\end{tabular}

TABLE III. THE FINAL DECISION MAKING

\begin{tabular}{|l|c|}
\hline \multicolumn{2}{|c|}{$\begin{array}{c}\text { Goal: Which electrical devices do you prefer to use during peak hours } \\
\text { when electrical price rate increases 33 percent? }\end{array}$} \\
\hline \multicolumn{1}{|c|}{ Appliance ranking } & Numerical priority \\
\hline 1- Spa Bath & 0.237 \\
\hline 2- Dish Washer & 0.235 \\
\hline 3- Home Computer & 0.183 \\
\hline 4- Vacuum Cleaner & 0.120 \\
\hline 5- TV & 0.112 \\
\hline 6- Hair Dryer & 0.065 \\
\hline 7- Iron & 0.049 \\
\hline
\end{tabular}

\section{B. Knapsack Problem (KP)}

Dynamic programming is one of the oldest methods in combinatorial optimization. It was used very early in particular for knapsack type problems [27]. The knapsack problem derives its name from the problem faced by a hitch-hiker who has to fill up his knapsack by selecting from various possible items those which will give him greatest satisfaction. It can be mathematically formulated by numbering the objects from 1 to $\mathrm{n}$ and showing a vector of binary variables $\mathbf{x}_{\mathbf{j}}(\mathrm{j}=1, \ldots, \mathrm{n})$ with the following meaning:

$$
x_{j}= \begin{cases}1 & \text { if object } \mathrm{j} \text { is selected; } \\ 0 & \text { otherwise }\end{cases}
$$

Then, $p_{j}$ is a measure of the profit given by objective $j, w_{j}$ is its size and $c$ is the size of the knapsack. The problem will be to select, from among all binary vectors $x$ satisfying the constraint

$$
\sum_{j=1}^{n} w_{j} x_{j} \leq c
$$

The one which maximizes the objective function [28].

$$
\sum_{j=1}^{n} p_{j} x_{j}
$$

This kind of knapsack problem is known as 0-1 Knapsack Problem.

The scenario described in the previous section is formulated as below:

To maximize $(0.237 \mathrm{SB}+0.235 \mathrm{DW}+0.183 \mathrm{HC}+0.12 \mathrm{VC}$

$+0.112 \mathrm{TV}+0.065 \mathrm{HD}+0.049 \mathrm{IR})$

Subject to constraint

$$
\begin{aligned}
& 0.493 \mathrm{SB}+0.373 \mathrm{DW}+0.013 \mathrm{HC}+0.093 \mathrm{VC}+0.4 \mathrm{TV}+ \\
& 0.088 \mathrm{HD}+0.93 \mathrm{IR} \leq 0.896
\end{aligned}
$$

This problem is solved by LINGO [29] software 12.0 as a powerful optimization software and the result shown in Fig. 2 reveals that if the consumer turns the Dishwasher off, then he saves the same cost during on-peak period as he does during off-peak hours. The optimal solution shows the total value of preferences is 0.765 ; meanwhile, according to consumer's preferences achieved by AHP method, the total value was 0.655. As indicated by figures in Table III, the Dishwasher was second priority in the ranking of appliances that the consumer decided to use during peak hours, and turning it off is in contrast to this preference; but on the other hand, the total value is maximized. This consumption pattern is efficient because the demand and amount of energy is decreased.

The Fractional Knapsack problem is able to solve the problem of how much consumption time is required so that the total cost of electricity remains unchanged during peak hours. By applying this algorithm, a fraction of an hour in kW.h should be a variable for each appliance, the methodology of which is not within the scope of this paper.

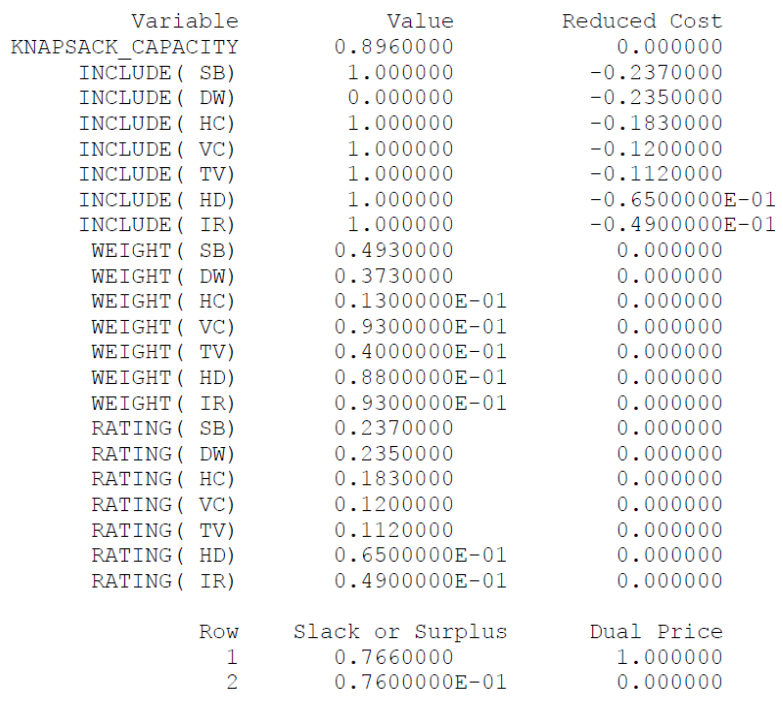

Figure 2. LINGO output for solving Knapsack problem 


\section{CONCLUSION}

Our approach to quantifying the end-users' preferences for managing their electrical appliances during peak hours offers a framework for home energy controllers in the smart grid for achieving an efficient energy consumption while simultaneously considering the end-users' lifestyles.

The underlying objective of demand response in a smart grid is to actively engage customers in modifying their consumption in response to pricing signals. The goal is to reflect supply expectations through consumer price signals or controls and enable dynamic changes in consumption relative to price. From the other side, home energy controllers are coupled with demand response to update end-users about their energy consumption information in regard to altering their consumption behaviour. On the other hand, electricity consumption by householders is not always rational and is influenced by the payment system along with human psychology factors. For this reason, we conducted a dynamic programming approach for achieving consumer preferences for managing the appliances when the price increases during peak hours. We applied an analytic hierarchy process for ranking the appliances according to their priority during peak hours. Our goal for the hierarchy was to determine which appliances consumers want to use when the electricity price rate increases; our criteria for ranking were: the cost of electricity, emergent, welfare and enjoyment of usage. These priorities were the values of appliances when we applied the binary Knapsack problem methodology with this constraint that the electrical cost in peak hours should not exceed that of off-peak hours. As a result, using the aforementioned scenario, it is substantiated that the optimal solution has the maximum value from the enduser viewpoint, but the solution may conflict with the preferred solution; if the home energy controller shows both scenarios to consumers through in-home displays, then making decisions for end-users would be more productive for the total grid system. Through this method, the end-users will not only better manage their budget, but also the demand on and consumption of energy in the grid will decrease. For a future approach, we offered the application of the Fractional Knapsack problem to specify how long each appliance should be used in constraint of not to exceed from the allocated cost or budget. Also, we determine that when there are several decision makers in a household, the group AHP is applicable and depending on the definition of various criteria in appliance usage, the fuzzy AHP would be more effective in a hierarchy.

\section{REFERENCES}

[1] P. Nabuurs, "Strategic Deployment Document For Eoroupe 's Elictricity Networks of the Future," N.V. KEMA, Draft 2008.

[2] S. Electric, "Leading the way in energy efficiency.",Schneider, 2009.

[3] A. Al-Mumin, O. Khattab, and G. Sridhar, "Occupants' behavior and activity patterns influencing the energy consumption in the Kuwaiti residences," Energy and Buildings, vol. 35, pp. 549-559, 2003.

[4] D. H. Danny Parker, Alan Meier, Richard Brown, "How much energy are we using? Potential of residential eenrgy demand feedback devices," Florida Solar Energy Center, Asilomar, CA 2006.

[5] S. Darby, "The effectiveness of feedback onenergy consumption :a review for DEFRA of the literature on metering, billing and direct displays," Environmental Change Institute, University of Oxford, 2006.
[6] A. Faruqui, S. Sergici, and A. Sharif, "The impact of informational feedback on energy consumption--A survey of the experimental evidence," Energy, vol. 35, pp. 1598-1608, 2010.

[7] G. R. Newsham and B. G. Bowker, "The effect of utility time-varying pricing and load control strategies on residential summer peak electricity use: A review," Energy Policy, vol. 38, pp. 3289-3296, 2010.

[8] S. Sa'ad, "Electricity demand for South Korean residential sector," Energy Policy, vol. 37, pp. 5469-5474, 2009.

[9] T. Ueno, F. Sano, O. Saeki, and K. Tsuji, "Effectiveness of an energyconsumption information system on energy savings in residential houses based on monitored data," Applied Energy, vol. 83, pp. 166-183, 2006.

[10] G. Wood and M. Newborough, "Dynamic energy-consumption indicators for domestic appliances: environment, behaviour and design," Energy and Buildings, vol. 35, pp. 821-841, 2003.

[11] G. Wood and M. Newborough, "Energy-use information transfer for intelligent homes: Enabling energy conservation with central and local displays," Energy and Buildings, vol. 39, pp. 495-503, 2007.

[12] Y. Yamamoto, A. Suzuki, Y. Fuwa, and T. Sato, "Decision-making in electrical appliance use in the home," Energy Policy, vol. 36, pp. 16791686, 2008.

[13] M. A. McNeil and V. E. Letschert, "Modeling diffusion of electrical appliances in the residential sector," Energy and Buildings, vol. 42, pp. 783-790, 2010.

[14] M. Aydinalp, V. Ismet Ugursal, and A. S. Fung, "Modeling of the appliance, lighting, and space-cooling energy consumptions in the residential sector using neural networks," Applied Energy, vol. 71, pp. 87-110, 2002.

[15] M. Aydinalp-Koksal and V. I. Ugursal, "Comparison of neural network, conditional demand analysis, and engineering approaches for modeling end-use energy consumption in the residential sector," Applied Energy, vol. 85 , pp. 271-296, 2008.

[16] V. Joon, A. Chandra, and M. Bhattacharya, "Household energy consumption pattern and socio-cultural dimensions associated with it: A case study of rural Haryana, India," Biomass and Bioenergy, vol. 33, pp. 1509-1512, 2009.

[17] L. G. Swan and V. I. Ugursal, "Modeling of end-use energy consumption in the residential sector: A review of modeling techniques," Renewable and Sustainable Energy Reviews, vol. 13, pp. 1819-1835, 2009.

[18] E. Sardianou, "Estimating energy conservation patterns of Greek households," Energy Policy, vol. 35, pp. 3778-3791, 2007.

[19] IndEco, "Demand side management and demand response in municipalities," IndEco Strategic Consulting Inc, Toronto, 2004.

[20] R. Earle, E. P. Kahn, and E. Macan, "Measuring the Capacity Impacts of Demand Response," The Electricity Journal, vol. 22, pp. 47-58, 2009.

[21] J. Torriti, M. G. Hassan, and M. Leach, "Demand response experience in Europe: Policies, programmes and implementation," Energy, vol. In Press, Corrected Proof, 2009.

[22] A. a. L. W. Faruqui, "Quantifying the Benefits Of Dynamic Pricing In the Mass Market," Edison Electric Institute, Washington, D.C. 2008.

[23] I. Røpke, T. Haunstrup Christensen, and J. Ole Jensen, "Information and communication technologies - A new round of household electrification," Energy Policy, vol. 38, pp. 1764-1773, 2009.

[24] T. L. Saaty, "Introduction to a modeling of social decision processes," Mathematics and Computers in Simulation, vol. 25, pp. 105-107, 1983.

[25] R. W. Saaty, "The analytic hierarchy process--what it is and how it is used," Mathematical Modelling, vol. 9, pp. 161-176, 1987.

[26] E. Choice, "Academic Products and Programs," EC11.5 ed: Epert Choice, 2010.

[27] U. Pferschy, "Dynamic Programming Revisited: Improving Knapsack Algorithms " Computing, pp. 419-430, 1999.

[28] S. Martello and P. Toth, Knapsack Problems: algorithms and computer implementations: Wiely, 1990.

[29] Lingo, "Integer Programming, Linear Programming, Nonlinear Programming, Global Optimization," 2010. 